\title{
Measuring differential item and test functioning across academic disciplines
}

Judith Runnels

\section{Correspondence:}

jrunnels@h-bunkyo.ac.jp

Hiroshima Bunkyo Women's

University, Bunkyo, Japan

\section{Springer}

\begin{abstract}
Differential item functioning (DIF) is when a test item favors or hinders a characteristic exhibited by group members of a test-taking population. DIF analyses are statistical procedures used to determine to what extent the content of an item affects the item endorsement of sub-groups of test-takers. If DIF is found for many items on the test, the final test scores do not represent the same measurement across groups in the population of test-takers. This is known as differential test functioning (DTF). DTF is of particular concern in tertiary level language tests, where test-takers often differ in academic discipline. This study examined the DIF and DTF of an in-house developed assessment designed to measure how well first year students of five academic disciplines achieved material over the course of a year of English language study. The DIF and DTF tests were performed using Rasch analysis, which controls for ability across groups, ensuring that items are only flagged if groups of test-takers of the same ability levels exhibit a significantly different probability of endorsing the item. The current analysis outlines the process for checking for DIF and DTF and finds that even though DTF is unlikely, there were several items that favored and hindered some majors. Recommendations for modification of items are made and the importance of establishing a process to check for DTF and DIF, especially when the test-takers are from different disciplines of study, is discussed.
\end{abstract}

Keywords: Rasch Analysis, Differential item functioning, Differential test functioning, Academic discipline

\section{Background}

While increasing numbers of Japanese universities are using commercially produced placement examinations for streaming classes by ability, the validity and relevance of the content of some of these tests has been questioned (Chapman, 2005). Weaver (2007) notes that while these assessments may be successful at providing an overall indication of test-takers' English knowledge, since they are written for the mass market, they do not provide specific enough conclusions by which to place students for that particular institution. Furthermore, they are irrelevant if the goal of the test is to determine the acquisition of material presented throughout the duration of tuition, rather than to determine the overall proficiency as an English language learner. As such, many universities are maintaining the usage of in-house designed assessments which can be tailored to the specific needs of their student population, language program or institutional demands.

(c) 2013 Runnels; licensee Springer. This is an Open Access article distributed under the terms of the Creative Commons Attribution License (http://creativecommons.org/licenses/by/2.0), which permits unrestricted use, distribution, and reproduction in any medium, provided the original work is properly cited. 
A major concern with the results of these in-house designed exams however, is that the interpretations and ultimate uses of test scores are valid and reasonable (Messick, 1989; Bachman, 1990) although the process of checking for validity for in-house designed tests is often overlooked (Weir, 2005). Furthermore, and particularly when it comes to institutional level testing, it is of the utmost importance that neither the test as a whole nor any individual item on the test favors any characteristic of a test-taker (Lumley \& O' Sullivan 2005). Differential item functioning (DIF) occurs when examinees with the same level of ability from two different groups have different probabilities of endorsing an item (Cole, 1993; Clauser \& Mazor, 1998). This can subsequently result in higher or lower scores for test-takers within that group (Swaminathan \& Rogers, 1990; Chang \& Mazzeo, 1994; Donoghue et al. 1993). Differential test functioning (DTF) is when the total score functions differently across groups such that the final scores do not represent the same measurement across the population of test-takers (Raju et al. 1995). The particular statistical approaches for examining these possibilities, known as DIF and DTF analysis respectively, detect the existence of some inherent characteristic in the test that is causing groups of test takers to respond differently after controls for ability are employed (Geranpayeh \& Kunnan, 2007; Karami, 2011). For DIF and DTF analyses, the Rasch model has been shown to provide a suitable method for equating abilities across groups (Karami, 2011; Wolfe, 2004).

The Rasch model uses probability to determine the relationship between a raw score and a person's ability, taking both item difficulty and person ability into account on an item-by-item basis (Bond \& Fox, 2001; Rasch, 1980). A participant's raw test score is converted into a ratio of success to failure and then into the logarithmic odds that the person will respond correctly to an item (a logit) (Smith, 2000). The logits are then plotted on a single scale and used as an estimate of ability for a test-taker and difficulty of an item. Rasch-based methods have the capability of identifying people or items that exhibit unexpected response patterns (Wright \& Stone, 1979). For DIF in particular, the Rasch model identifies items for which being a member of a certain sub-group of test-takers affects the probability of endorsement of that item when compared to other groups.

Rasch analysis has most commonly been used to measure differences in gender, ethnicity and native language on pedagogical performance tests (Meade \& Fetzer, 2009). In terms of language, Chen and Henning (1985) were one of the first researchers in language to employ a Rasch analysis for DIF. They examined bias in a university placement test for Chinese and Spanish test takers. Elder (1996) also used Rasch to analyze whether language background led to DIF on a test of English. Takala and Kaftandjieva (2000) modified the Rasch model to investigate DIF on the vocabulary section of Finnish Foreign Language Certificate Examination. All of the aforementioned scholars note that any time there are differences in test-takers, addressing the potential issue of DIF is important.

DIF analysis has also been used in education to measure differences across academic disciplines of study (Alavi et al. 2011). Alderson and Urquhart (1985) for example, studied test-takers with the same first language, using academic major of study to define the sub-groups. They analyzed an English-for-specific-purposes reading test and found that academic discipline affected test performance, although the effects were inconsistent. Pae (2004) performed DIF analyses on the National Korean University and College entrance exam to determine that nearly a third of items favored either a science or a humanities major. Alavi et al. (2011) studied DIF in the University of Tehran English 
Proficiency Test for humanities and, science and engineering groups and found items that both favored and hindered certain majors. Weaver (2007) also found that a DIF analysis pinpointed differences between reading passages which benefited science or humanities majors, depending on the content of the passage.

The test-takers of the current analysis are of five different majors, and it is therefore important to consider the possibility of DIF to verify that the test is not favoring one major over another. The test was designed to determine how well students had acquired material that they had studied throughout their first year of English study. While students of all five majors participated in the same English classes, some of the curriculum may have favored some disciplines over others, potentially affecting test performance. It is therefore imperative to ensure that the test and each individual item are taking equivalent measurements across groups (Camilli, 2006). Three hypotheses will be tested: the first hypothesis is that the item has the same difficulty across two groups, the second is that the item has the same difficulty as the average difficulty for all groups, and the third hypothesis is that the item has no overall DIF across all groups (Linacre, 2004). If any of these hypotheses are rejected, then this would indicate that some of the items are exhibiting DIF and checks for DTF will be performed by comparing mean DIF scores across majors. Since this test was designed to measure how well students achieved material from a year of English study, and all students participated in the same mixed-major English classes, no DIF is expected. In the event that some degree of DIF is found, and that it is large enough to impact students' final grades, subsequent measures such as score adjustment, may be required to compensate for the inherent favoring in the test. Additionally, item modification may also be required prior to future administrations of the assessment.

\section{Method}

\section{Participants}

The test-takers were 325 female first year students from Hiroshima Bunkyo Women's University (aged 18 and 19 years), a private university in Hiroshima City, Japan. They were in one of eleven different mixed-major classes and had completed two 90 minute lessons a week throughout two semesters of the academic year. Japanese (L1) and English (L2) are respectively the first and second languages of all test-takers.

\section{Instrument}

The test (administered in 2012) consisted of 61 multiple choice questions in 3 sections (reading, listening and grammar). The assessment tool was designed to determine how well students had acquired material from curriculum they studied in two periods of 90 minutes every week for the previous year and was previously analysed for misfit to the Rasch model by Runnels (2012) who found no misfitting infit and very little misfitting outfit. The test made up $15 \%$ of the students' final grade for the semester and lasted a total of 76 minutes.

\section{Procedure}

The test was taken in the students' regular classrooms during their usual class time. WINSTEPS $^{\circledR}$ Rasch software Version 3.72.4 (Linacre, 2008) was used to analyze the 
results of the test to produce both the item strata and the differential item functioning analysis outputs. The two types of fit statistics (infit and outfit) were also measured.Infit statistics consist of mean-square (MNSQ) values, and outfit statistics are composed of z-standardized scores (ZSTD). The MNSQs represents the size of the misfit to the Rasch model and the ZSTDs the significance of the misfit. Essentially, infit is used to judge unexpected response patterns where the test is targeting ability, while outfit statistics reflect guessing or mistakes (Linacre, 2007). Acceptable values for MNSQs are between 0.7-1.3 and from -2.0 to 2.0 for ZSTDs on a low stakes test (Bond \& Fox, 2007).

Item separation strata are used to identify statistically distinct difficulty levels according to the responses to all items (Wright \& Masters, 2002). They demonstrate the range of item-difficulties that have been included. Item strata are calculated using the following formula (Beglar, 2010):

$$
\text { Item strata }=(4 \text { Gitem }+1 / 3)
$$

where Gitem is the Rasch item separation value (derived by dividing the item standard deviations by the average measurement error). Smith (2001) requires a minimum two level difficulty level in order to deem the measurement tool representative of the assessed content.

Each item on the test was examined for DIF. To test the three hypotheses, WINSTEPS $^{\circledR}$ compares the group mean scores on each item, the item difficulty to the mean difficulty for all groups on that item, and that the item DIF across all groups. For the current analysis, these tests are performed in the reverse order, starting with the third hypothesis, to determine which items are exhibiting DIF across majors. If there are no items with any evident DIF, the second hypothesis will be checked to determine if any items have a statistically significant differing difficulty to the average difficulty across majors. Finally, if necessary, items which have different difficulties across two majors will also be measured (the first hypothesis) to determine where these differences specifically lie. Altogether, testing these three hypotheses will also reveal if DTF is a concern for this assessment.

These hypotheses use a t-test (Wright \& Stone, 1979) to determine the amount of DIF (Smith, 2004). WINSTEPS ${ }^{\circledR}$ (Linacre, 2010) employs the following formula:

$$
\begin{aligned}
& t=d_{i 2}-d_{i 1} \\
& \sqrt{ }\left(s^{2}{ }_{l 2}-s^{2}{ }_{11}\right)
\end{aligned}
$$

where $\mathrm{d}_{\mathrm{i} 2}$ is the difficulty of item $I$ in calibration based on two groups, $\mathrm{d}_{\mathrm{i} 1}$ is the difficulty of item $i$ in calibration $l, \mathrm{~s}_{11}^{2}$ is the standard error of the estimate for $\mathrm{d}_{\mathrm{i} 1}$ and $\mathrm{s}_{l 2}^{2}$ is the standard error of the estimate for $\mathrm{d}_{\mathrm{i} 2}$ (Alavi \& Karami, 2010). Rather than calculating fit statistics for each individual item, for DIF tests, Rasch produces the betweenclass mean squares as the Between-Group fit statistics (see Smith \& Plackner, 2009). The between-group fit indices also test the hypothesis that the dispersion of the group measures fits with the expectations of the Rasch model.

Alavi and Karami (2010) suggest that a major problem with using significance tests in DIF analyses is that they are sensitive to sample size. This means that if sample sizes are large, some differences, even small ones, will be significant. The opposite is true for small sample sizes: large differences between two groups may not be significant if the 
sample sizes are small. In the present study, the sample size can reasonably be considered as large and therefore, using the significance tests directly from the software output, may not be justified. Linacre (2007) notes that for the first hypothesis, which compares across two majors, that the results of a Rasch analysis test for DIF are questionable. Despite statistically significant differences, the impact of one item may have too small an influence on the meaning of the test results. As a result, in the current study, both statistical significance and a logit difference of at least 0.5 are required before any action to address item bias will be taken (Linacre, 2007). The former will be addressed by employing a Bonferroni correction test, as described by Alavi \& Karami (2010). This entails distributing the alpha level (in this case, 0.05) across all of the comparisons such that 0.05 is the sum of the alpha levels (see Thompson, 2006). Then, the alpha level is divided by the number of items, producing a new level at which to judge significance.

\section{Results}

\section{Summary statistics}

The mean score of the test was $55.7 \%(S D=12.6 \%)$. Three items $(46,49,71)$ fell outside the acceptable range for outfit, all with statistically significant ZSTDs (Runnels, 2012).

Summary statistics for the test are shown in Table 1. The mean MNSQ for both infit and outfit falls within the acceptable range for a low-stakes test (Bond \& Fox, 2007). Cronbach's alpha for items is 0.99 and the separation strata for non-extreme items (items for which there was not a $0 \%$ or a $100 \%$ success rate) was 8.54 : this many distinct difficulty levels demonstrates that the scale discriminated effectively between testtakers (Smith, 2001).

\section{Differential item analyses}

The results of the hypothesis test that items have no overall DIF across all groups are shown in Table 2 . Only items that are statistically significant at the $\mathrm{p}<0.05$ value are displayed. It can be seen that there is only a single item which exhibits has statistically significant DIF (Item 5) and that it is exhibiting DIF across all majors. The Bonferroni correction test puts the new significance level at 0.0008 , at which even this item is no longer significant.

For the hypothesis that the item has the same difficulty as its average difficulty for all groups, statistically significant differences at an alpha level of 0.05 are shown below in Table 3 (a total of 6 items as follows: 5, 17, 23, 29, 41, 49). There are 6 items across the

Table 1 Summary statistics for person and item measures*

\begin{tabular}{llllllll}
\hline Person & Score & Count & Measure & Infit & & Outfit \\
\hline Mean & 34.3 & 61 & & MNSQ & ZSTD & MNSQ & ZSTD \\
\hline S.D. & & & & 1.0 & .0 & 99 & .0 \\
\hline Items & 183 & 325 & 50.00 & .14 & 1.0 & .25 & 1.0 \\
\hline Mean & 72.4 & .7 & 12.14 & .07 & 1.5 & .99 & .15 \\
\hline S.D. & & & & & & 1.7 \\
\hline
\end{tabular}

* MNSQ - Mean-square, ZSTD - standardized z-score. 
Table 2 Items with DIFAcross all groups*

\begin{tabular}{lllllll}
\hline Person class & $\begin{array}{l}\text { Summary DIF } \\
\text { Chi-square }\end{array}$ & D.F. & Prob. & $\begin{array}{l}\text { Between-Class } \\
\text { Mean-Square }\end{array}$ & Item T=ZSTD & Item number \\
\hline 5 & 10.2878 & 4 & 0.0357 & 0.5532 & -0.5242 & 5 \\
\hline
\end{tabular}

*The first column, Person Class is the count of groups (in this case, major) with estimable DIF for the item. The Summary DIF Chi-Square column is the sum of the squared normalized t-statistic value for each item. D.F. represents the degrees of freedom or the count of majors minus 1 contributing to the chi-square. The Prob. is the probability of the chi-square (any value under 0.05 is statistically significant) followed by the Between-Class Mean-Square. The sixth column, the Item T=ZSTD represents the significance of the Mean-Square standardized as a unit-normal deviate (t-statistic with infinite degrees of freedom). The final column, the item number, accords with the question number on the test.

5 majors that have statistically significant different difficulties. Applying the Bonferroni correction test to this analysis reduces the alpha level to 0.0008 . At this level of significance, there are no items that are significantly different across groups.

Given these results, the mean significance DIF and p-value for each major was calculated and is shown in Figure 1. It can be seen that neither major had any DIF scores over 0.5 logits, eliminating the possibility of DTF.

The final hypothesis is tested to determine specifically which items exhibit differences between majors. Table 4 displays the output for the hypothesis that the item has the same difficulty across two groups (statistically significant differences only). In total, there are 14 items exhibiting significant differences $(2,5,17,20,23,29,30,32,34,35$, $41,48,49)$. Following a Bonferroni test, of these 14 items, at an alpha level of $\mathrm{p}<0.0008$, none of these items are significant.

Summarizing all of the tests herein, there are a total of 14 items displaying DIF of some kind. Out of the 14 items, 7 of them were highlighted by only one of the hypothesis tests (items $2,20,30,32,34,35,48)$, six items by two of the tests $(17,23,29,41$, 49) and one item by all three of the hypothesis tests (item 5). However, regarding the results of the third hypothesis (shown in Table 4), items 35 and 48 had significantly different scores for more than just two majors. Given all of this, these analyses have provided a list of 8 items that require revisiting prior to future administrations $(5,17,23$, $29,35,41,48 \& 49)$. Item 5 is likely the only item that requires definite modification.

\section{Discussion}

The results of the current study indicate that there are a potential 14 items with significant DIF on the test, although the evidence is strong enough to conclude that there is

Table 3 Item difficulty by major compared to average difficulty for all groups*

\begin{tabular}{llllllllll}
\hline Person class & Count & DIF score & DIF measure & DIF Size & DIF S.E. & DIF t & Prob. & Item number \\
\hline B & 49 & -0.16 & 70.32 & 9.62 & 4.0 & 2.4 & 0.0202 & 5 \\
\hline E & 19 & -0.23 & 65.66 & 10.65 & 5.16 & 2.06 & 0.0547 & 17 \\
\hline $\mathrm{E}$ & 19 & .33 & 38.88 & -17.65 & 6.5 & -2.71 & 0.0147 & 23 & \\
\hline $\mathrm{C}$ & 49 & .15 & 41.99 & -7.39 & 3.31 & -2.24 & 0.0301 & 29 \\
\hline $\mathrm{D}$ & 67 & .12 & 45.52 & -5.47 & 2.69 & -2.03 & 0.0462 & 41 \\
\hline $\mathrm{B}$ & 49 & .14 & 42.47 & -6.63 & 3.30 & -2.01 & 0.500 & 49 \\
\hline
\end{tabular}

*The Person Class column represents the test-takers' majors (Early Childhood Education (A),Welfare (B), Psychology (C), Nutrition (D) and Global Communication (E)). COUNT is the number of observations of the classification used for DIF estimation (Linacre, 2007). Following this is the DIF SCORE, which represents the difference between the observed and the expected average observations. The DIF MEASURE is the item difficulty for this class. The DIF SIZE column indicates the difference between the DIF MEASURE for this class and the baseline difficulty where a positive value shows that the item is more difficult than expected for that major, and a negative value shows that that item is favoring the according major. DIF S.E. indicates the standard error of the difference and the DIF $t$ is the student's t-statistic. PROB. is the probability of the $t$-value and the last column corresponds to the item number on the test. 


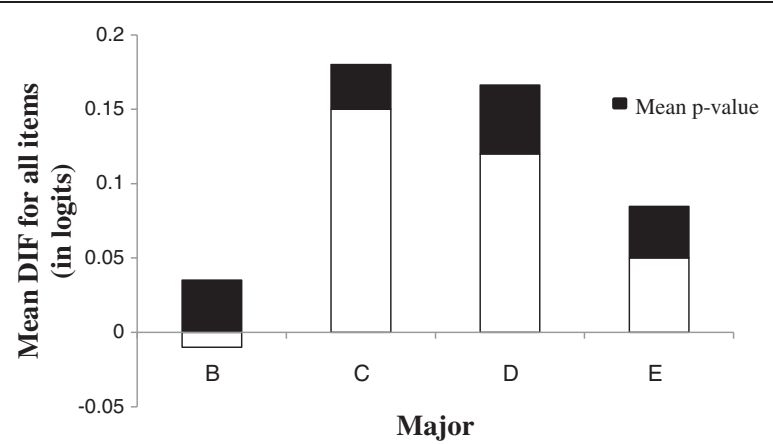

Figure 1 The mean DIF levels for all majors in logits where B is Welfare, C is Psychology, D is Nutrition and E is Global Communication.

only a single item (5) that is causing enough DIF for serious concern in that it may have impacted the overall scores on the test. However, since it was only a single item out of a total of 61 , this represents $1.6 \%$ of the total test. Since the scores of this test contributed to $15 \%$ of students final grades, this item was worth $0.24 \%$ of student's overall grades. If any Welfare or Nutrition majors were on a grade change cusp and $0.24 \%$ would boost them up to the next grade level, or prevent them from failing, then perhaps action might be taken to adjust their scores, but at such a small percentage,

Table 4 Item score significant differences across major*

\begin{tabular}{|c|c|c|c|c|c|c|}
\hline Item & Majors & DIF Contrast & Joint S.E. & Welch $t$ & d.f & Prob \\
\hline 2 & $A D$ & -7.25 & 3.16 & -2.3 & 154 & 0.0229 \\
\hline \multirow[t]{2}{*}{5} & $A B$ & -12.08 & 4.4 & -2.75 & 32 & 0.0072 \\
\hline & $B D$ & 12.23 & 4.77 & 2.56 & 99 & 0.0118 \\
\hline \multirow[t]{2}{*}{17} & $A E$ & -11.62 & 5.46 & -2.13 & 32 & 0.0411 \\
\hline & $B E$ & -12.71 & 5.97 & -2.13 & 39 & 0.0395 \\
\hline 20 & $C E$ & -14.13 & 6.21 & -2.28 & 39 & 0.0285 \\
\hline \multirow[t]{4}{*}{23} & $A E$ & 19.03 & 6.75 & 2.82 & 29 & 0.0086 \\
\hline & $B E$ & 16.78 & 7.17 & 2.34 & 35 & 0.0251 \\
\hline & $C E$ & 19.17 & 7.20 & 2.66 & 36 & 0.0115 \\
\hline & $D E$ & 18.54 & 6.99 & 2.65 & 33 & 0.0122 \\
\hline \multirow[t]{2}{*}{29} & $A C$ & 9.17 & 3.76 & 2.44 & 103 & 0.165 \\
\hline & $D C$ & 9.61 & 4.17 & 2.3 & 105 & 0.0232 \\
\hline 30 & $A E$ & -12.04 & 5.21 & -2.31 & 34 & 0.0269 \\
\hline 32 & $A D$ & 10.99 & 5.23 & 2.1 & 129 & 0.0377 \\
\hline 34 & $A C$ & 8.28 & 3.59 & 2.31 & 106 & 0.0229 \\
\hline \multirow[t]{2}{*}{35} & $A D$ & -7.54 & 3.61 & -2.09 & 106 & 0.0393 \\
\hline & $C A$ & 7.54 & 3.62 & 2.09 & 106 & 0.0393 \\
\hline \multirow[t]{2}{*}{41} & $C D$ & 8.81 & 4.04 & 2.18 & 108 & 0.0315 \\
\hline & $D A$ & -6.80 & 3.24 & -2.1 & 151 & 0.0372 \\
\hline \multirow[t]{2}{*}{48} & $A D$ & -6.69 & 3.18 & -2.1 & 152 & 0.0371 \\
\hline & $A E$ & -12.9 & 5.46 & -2.36 & 32 & 0.0244 \\
\hline 49 & $A B$ & 8.69 & 3.75 & 2.31 & 103 & 0.0226 \\
\hline
\end{tabular}

*The DIF CONTRAST measure illustrates the difference between the item measures, or the difference in difficulty of the item between the two groups (a difference of at least 0.5 logits is required for the DIF to be noticeable). A positive DIF contrast represents that the item was more difficult for the CLASS (major) that is listed on the left whereas a negative DIF contrast demonstrates that the item was easier for the major on the left. The PROB illustrates the probability of observing this amount of contrast by chance. The JOINT S.E. is the standard error of the DIF CONTRAST, the Welch $t$ gives the DIF significance as a t-statistic. 
this possibility is unlikely and adjustment of the scores is not likely necessary. In terms of future action however, even though overall the mean DIF for each major was negligible enough that DTF was not found, future administrations of this test could certainly benefit from some modification of items; particularly item 5 and possibly the additional 7 items that were highlighted by two of the tests employed in the analysis. The DIF analyses however, make no suggestion as to how modifications can be made, and incorporating changes is sometimes a trial-and-error process (Alavi \& Karami, 2011) since the reason as to why the DIF exists for this test is only speculative.

For the most questionable item, the relevant portion of the reading passage that this item is based on is as follows:

We met on the first day of our third year of Junior High School when we were 14 and now we are both first year university students. The exact item is as follows:

5. How long have Yuriko and Mari been friends?
a. More than 3 years
b. More than 4 years
c. More than 5 years
d. More than 6 years

This item requires some pre-existing knowledge about how old students are when they enter university. Furthermore, more than 6 years is not mutually exclusive of the other options of more than 3,4 , and 5 years which suggests a potential wording issue with the distractors. Despite this, Early Childhood Education majors and Nutrition majors of the same ability found this item easier than Welfare majors. This could be a matter of simple arithmetic or better awareness of how many years between junior high school and university. Either way, this item's distractors need to perhaps be made more specific or more information is required in the passage.

Item 23 was another that exhibited DIF to some extent (see Table 4). This item was a fill in the blank from a postcard as follows:

It is _ 23 _ city.

The options were:

a. really interesting

b. really interested

c. a really interesting

d. a really interested

For this item, Global Communication majors of the same ability performed significantly better than every other major. This is perhaps no surprise because this item is a grammar question. Despite controls for ability, these students have greater grammar resources to pull from considering that they spend large amounts of their tuition studying English grammar. In this item's case, the fact that the English majors performed at higher levels is not necessarily a negative result since it is demonstrating that their grammar knowledge is superior to other majors of the same overall language ability. However, the question of why there was not a greater number of items like this (items 
where the Global Communication majors had some sort of internal advantage) is now raised. Further explorations could perhaps determine which students were affecting the overall DIF.

In the listening section of the test, item 48 required students to, after listening to a self-introduction of an imaginary classmate, respond to the following question:

48. How old is Julie's sister?
a. 2
b. 16
c. 18
d. 20

The relevant portion of the listening passage was as follows: "I am 18 years old and I have 1 sister. She is two years younger than I am."

In this item, Early Childhood Education majors of the same ability are more likely to correctly endorse this item than both Global Communication and Nutrition majors. As with item 5, this could perhaps be due to the arithmetic involved, note-taking ability or it could be related to short-term memory, since this information was presented to testtakers at the start of a one minute speech. It did not necessarily call on English comprehension knowledge of any kind, and was likely more related to either short-term memory or an ability to note what may be important information later on (all students could make notes throughout the listening passages if they chose to). In either case, the listening passage could be adjusted by breaking it down into chunks so that the answer to the question is not presented an entire minute prior to being able to respond.

\section{Conclusions}

Overall, this assessment did in fact seem to hold up reasonably well under DIF scrutiny, so that major concern does not need to be given to differences between sub-groups of test-takers. Nonetheless, the process for interpreting DIF results has not been wellestablished. Alavi \& Karami (2011) examined experts' interpretations of DIF results to determine the real cause of the DIF. They found inconsistencies among the opinions, deeming DIF interpretations ad hoc. They suggest that a systematic mechanism to interpret DIF results is required and that despite the lack of specificity for the interpretation of items exhibiting DIF, the process of checking for its existence should not be ignored.

The goal herein however, was not to account for all of the possible explanations for the significant DIFs. Rather, the ultimate purpose can be seen as a description of a test evaluation the goal of which was to ensure that the measurements being taken across groups were consistent. It was assumed that the measurements taken by the test would be equivalent across majors. Indeed this did occur for the most part, but there was a chance that some of the items might have favored one major enough to impact their grades in the course. All of the students participated in the same mixed-major classes, meaning that they shared relatively equivalent learning environments, and to allow students' final scores to be impacted by a single item or two, would be an unfair outcome to those students whom it did affect, especially if this favoritism was as a result of some inherent characteristic of test items. To avoid this, checks for DIF must be performed, 
whether or not the reason for the DIF is easily determinable. Ultimately, this evaluation produced useable results that may be able to provide direction for future improvement of the instrument. DIF analyses, especially when there are several different sub-groups of test-takers, with potentially different characteristics, should not be overlooked.

\section{Competing interests}

The author declares that she has no competing interests.

\section{Authors' information}

Judith Runnels is currently lecturer in the Global Communication Department at Hiroshima Bunkyo Women's

University where she is Head of Assessment. Her research interests include testing and evaluation.

Received: 21 March 2013 Accepted: 21 March 2013

Published: 12 April 2013

\section{References}

Alavi, SM, \& Karami, H. (2010). Differential item functioning and ad hoc interpretations. TELL, 4(1), 1-18.

Alavi, SM, Rezaee, AA \& Amirian, SMR. (2011). Academic discipline DIF in an English language proficiency test. Journal of English Language Teaching and Learning, 5(7), 39-65.

Alderson, JC, \& Urquhart, A. (1985). The effect of students' academic discipline on their performance on ESP reading tests. Language Testing, 2, 192-204.

Bachman, LF. (1990). Fundamental considerations in language testing. Oxford: Oxford University Press.

Beglar, D. (2010). A Rasch-based validation of the vocabulary size test. Language Testing, 27, 101-118.

Bond, TG, \& Fox, CM. (2001). Applying the Rasch model: Fundamental measurement in the human sciences. Mahwah, NJ: LEA.

Bond, TG, \& Fox, CM. (2007). Applying the Rasch model: Fundamentalmeasurement in the human sciences (2nd ed.). New Jersey: Lawrence Erlbaum.

Camilli, G. (2006). Test fairness. In R Brennan (Ed.), Educational measurement (4th ed., pp. 221-256). New York: American Council on Education \& Praeger series on higher education.

Chang, HH, \& Mazzeo, J. (1994). The unique correspondence of the item response function and item category response functions in polytomously scored item response models. Psychometrika, 59, 391-404.

Chapman, M. (2005). A case study of the need for change in the language testing policies of a Japanese corporation. JLTA Journal, 8, 51-67.

Chen, Z, \& Henning, G. (1985). Linguistic and cultural bias in language proficiency tests. Language Testing, 2(2), 155-163.

Clauser, EB, \& Mazor, MK. (1998). Using statistical procedures to identify differentially functioning test items. Educational Measurement: Issues and Practice, 17, 31-44.

Cole, NS. (1993). History and development of DIF. Hillsdale, NJ, England: Lawrence Erlbaum Associates, Inc.

Donoghue, JR, Holland, PW, \& Thayer, DT. (1993). A Monte Carlo study of factors that affect the mantel-haenszel and standardization measures of differential item functioning. In PW Holland \& H Wainer (Eds.), Differential item functioning (pp. 137-166). Hillsdale, NJ: Lawrence Erlbaum Associates.

Elder, C. (1996). The effect of language background on "foreign" language test performance: The case of Chinese, Italian, andModern Greek. Language Learning, 46, 233-282.

Geranpayeh, A, \& Kunnan, AJ. (2007). Differential item functioning in terms of age in the certificate in advanced English examination. Language Assessment Quarterly, 4, 190-222.

Karami, H. (2011). Detecting gender bias in a language proficiency test. International Journal of Language Studies, 5(2), 27-38.

Linacre, JM. (2004). Test validity and Rasch measurement: Construct, content, etc. Rasch Measurement Transactions, 18(1), 970-971.

Linacre, JM. (2007). A user's guide to WINSTEPS-MINISTEP: Rasch-model computer programs. Chicago, IL. winsteps.com.

Linacre, JM. (2008). A user's guide to winsteps/ ministeps: Rasch model computer programs. Chicago, IL. winsteps.com.

Linacre, JM. (2010). Winsteps ${ }^{\oplus}$ (Version 3.70.0) [Computer Software]. Beaverton, Oregon: Winsteps.com.

Lumley, T, \& O' Sullivan, B. (2005). The effect of test-taker gender, audience and topic on task performance in tapemediated assessment of speaking. Language Testing, 22(4), 415-437.

Meade, AW, \& Fetzer, M. (2009). Test bias, differential prediction, and a revised approach for determining the suitability of a predictor in a selection context. Organizational Research Methods, 12(4), 738-761.

Messick, S. (1989). Validity. In RL Linn (Ed.), Educational measurement (pp. 13-103). New York: Macmillan.

Pae, T. (2004). DIF for learners with different academic backgrounds. Language Testing, 21, 53-73.

Raju, NS, van der Linden, WJ, \& Fleer, PF. (1995). IRT-based internal measures of differential functioning of items and tests. Applied Psychological Measurement, 19, 353-368.

Rasch, G. (1980). Probabilistic models for some intelligence and attainment tests. Chicago: University of Chicago Press (Expand ed).

Runnels, J. (2012). Using the Rasch model to validate a multiple choice English achievement test. International Journal of Language Studies, 6(4), 141-155.

Smith, EV. (2000). Metric development and score reporting in Rasch measurement. Journal of Applied Measurement, 1 , $303-326$

Smith, EV. (2001). Evidence for the reliability of measures and validity of measure interpretation: A Rasch measurement perspective. Journal of Applied Measurement, 2, 281-311.

Smith, R. (2004). Detecting item bias with the Rasch model. Journal of Applied Measurement, 5(4), 430-449.

Smith, RM, \& Plackner, C. (2009). The family approach to assessing fit in Rasch measurement. Journal of Applied Measurement, 10(4), 424-437.

Swaminathan, H, \& Rogers, HJ. (1990). Detecting differential item functioning using logistic regression procedures, Journal of Educational Measurement, 27, 361-370. 
Takala, S, \& Kaftandjieva, F. (2000). Test fairness: A DIF analysis of an L2 vocabulary test. Language Testing, 17, 323-340. Thompson, B. (2006). Foundations of behavioral statistics: An insight-based approach. London: The Guilford Press. Weir, CJ. (2005). Language testing and validation: An evidence-based approach. Hampshire, UK: Palgave-Macmillan. Weaver, C. (2007). A Rasch-based evaluation of the presence of item bias in a placement examination designed for an EFL reading program. In T. Newfields, I. Gledall, P. Wanner, \& M. Kawate-Mierzejewska (Eds.). Second Language Acquisition - Theory and Pedagogy: Proceedings of the 6th Annual JALT Pan-SIG Conference. Retrieved September 21, 2012 from http://jalt.org/pansig/2007/HTML/Weaver.htm.

Wolfe, EW. (2004). Equating and item banking with the Rasch model. In E Smith \& R Smith (Eds.), Introduction to Rasch measurement (pp. 360-390). Maple Grove, MN: JAM Press.

Wright, BD, \& Masters, GN. (2002). Number of person or item strata. Rasch MeasurementTransactions, 16, 888.

Wright, BD, \& Stone, MH. (1979). Best test design. Chicago: MESA Press.

doi:10.1186/2229-0443-3-9

Cite this article as: Runnels: Measuring differential item and test functioning across academic disciplines.

Language Testing in Asia 2013 3:9.

Submit your manuscript to a SpringerOpen ${ }^{\circ}$ journal and benefit from:

- Convenient online submission

- Rigorous peer review

- Immediate publication on acceptance

- Open access: articles freely available online

- High visibility within the field

- Retaining the copyright to your article

Submit your next manuscript at $>$ springeropen.com 